\title{
Viewing the Personality Traits Through a Cerebellar Lens: a Focus on the Constructs of Novelty Seeking, Harm Avoidance, and Alexithymia
}

\author{
Laura Petrosini $^{1,2} \cdot$ Debora Cutuli $^{1,2} \cdot$ Eleonora Picerni $^{1,2} \cdot$ Daniela Laricchiuta $^{1,2}$
}

(C) Springer Science+Business Media New York 2016

\begin{abstract}
The variance in the range of personality trait expression appears to be linked to structural variance in specific brain regions. In evidencing associations between personality factors and neurobiological measures, it seems evident that the cerebellum has not been up to now thought as having a key role in personality. This paper will review the most recent structural and functional neuroimaging literature that engages the cerebellum in personality traits, as novelty seeking and harm avoidance, and it will discuss the findings in the context of contemporary theories of affective and cognitive cerebellar function. By using region of interest (ROI)- and voxel-based approaches, we recently evidenced that the cerebellar volumes correlate positively with novelty seeking scores and negatively with harm avoidance scores. Subjects who search for new situations as a novelty seeker does (and a harm avoiding does not do) show a different engagement of their cerebellar circuitries in order to rapidly adapt to changing environments. The emerging model of cerebellar functionality may explain how the cerebellar abilities in planning, controlling, and putting into action the behavior are associated to normal or abnormal personality constructs. In this framework, it is worth reporting that increased cerebellar volumes are even associated with high scores in alexithymia, construct of personality characterized by impairment in cognitive, emotional, and affective processing. On such a basis, it seems necessary to go
\end{abstract}

Laura Petrosini

laura.petrosini@uniroma1.it

1 IRCCS Fondazione Santa Lucia, via Ardeatina 306, 00179 Rome, Italy

2 Department of Psychology, University "Sapienza" of Rome, Via dei Marsi 78, 00185 Rome, Italy over the traditional cortico-centric view of personality constructs and to address the function of the cerebellar system in sustaining aspects of motivational network that characterizes the different temperamental traits.

Keywords Personality traits $\cdot$ ROI- and voxel-based morphometry $\cdot$ Emotion regulation $\cdot$ Alexithymia . Embodiment

\section{Introduction}

The word "personality" originates from the Latin persona, which means mask. In the theatre of the ancient world, the mask was not used as a device to disguise the identity of a character but, conversely, it was a convention to represent or typify that character. In psychology, personality is a dynamic and organized ensemble of features that influence cognition, emotion, motivation, and behavioral patterns in various situations [1]. It refers to the pattern of thoughts, feelings, and social adjustments exhibited over time that consistently influence expectations, self-perceptions, values, and attitudes of a subject as well as the reactions to other people, problems, and stress. In this framework and in accordance with the American Psychological Association [2], personality traits are considered "enduring patterns of perceiving, relating to, and thinking about the environment and oneself that are exhibited in a wide range of social and personal contexts." Theorists generally assume that traits are relatively stable over time, differ among individuals, and influence behavior [1]. Personality is viewed as instigator of propensities given that it influences cognitive, affective, and behavioral inclinations in response to real or imagined stimuli and orients individuals consistently across domains and situations. However, individuals can override 
their initial inclinations, so that their ultimate behavior is subjected to strategic planning and other forms of self-regulation.

In the latter half of the twentieth century, various models and taxonomies have been proposed to explain personality and describe the diversity of personality characteristics with a finite number of independent dimensions. The most influential personality theories include Eysenck's personality model [3], Gray's Reinforcement Sensitivity Theory [4], Tellegen's model [5], Big Five personality trait model [6], and Cloninger's psychobiological model [7]. In all these models, it is suggested that the personality traits are based on the joint influence of genetics, biology, and environment [1].

\section{Cloninger's Model of Temperamental Traits}

On the basis of family background, longitudinal developmental, psychometrical, neuropharmacological, and neuroanatomical studies, Cloninger identified four primary-basic personality temperaments and three characters that can be measured with his Temperament and Character Inventory (TCI) [7, 8]. While the character traits are produced by learning, maturation, and socio-cultural factors and evolve across life span, the temperamental traits are potentially associated with a specific genetic and biological substrate, relatively consistent and stable over time $[8,9]$. It is postulated that they determine disposition to attachment and early emotions of fear and anger as well as automatic behavioral responses to danger, novelty, and reward. Novelty seeking (NS), harm avoidance (HA), reward dependence (RD), and persistence (P) are the four temperamental traits described in the TCI [8].

The NS scale consists of four sub-scales and refers to the tendency to action behavior. High NS scores stand for high tendency to exploratory activity in response to novelty, impulsive decision-making even with incomplete information, extravagant approach to reward cues (money, energy, and feelings), and quick loss of temper. The advantages of high NS are excitability, curiosity, enthusiasm, and quick engagement with whatever is new. Conversely, the disadvantages are indifference, lack of reflection, intolerance to monotony, anger, inconsistence in relationships, and quick disengagement whenever a wish is frustrated, running away from boring or uncomfortable situations or contexts. The NS1 sub-scale (exploratory excitability vs. stoic rigidity) is related to the tendency versus avoidance to explore unfamiliar places and situations; the NS2 sub-scale (impulsiveness vs. reflection) is related to the tendency versus avoidance to be excitable, impressionistic, and dramatic, to make decisions with incomplete information, to poorly control impulses; the NS3 sub-scale (extravagance vs. reserve) is related to the tendency versus avoidance to be extravagant with money, energy, and feelings and to live "at the edge"; the NS4 sub-scale (disorderliness vs. regimentation) is related to the tendency versus avoidance to lose temper and to run away from whatever is frustrating, boring, or uncomfortable.

The HA scale consists of four sub-scales and refers to a tendency to inhibition of behavior in response to signals of punishment. High HA scores stand for high tendency to pessimistic worry in anticipation of problems, fear of uncertainty, shyness, avoidance to be assertive in social situations, and rapid fatigability. Adaptive advantages of high HA are cautiousness and careful planning when hazard is likely. The disadvantages occur when hazard is unlikely but, however, anticipated which leads to maladaptive inhibition and anxiety. The HA1 sub-scale (anticipatory worry vs. uninhibited optimism) is related to the avoidance versus tendency to anticipate harm in unfamiliar situations; the HA2 sub-scale (fear of uncertainty) is related to the avoidance versus tendency to tolerate potentially dangerous circumstances; the HA3 sub-scale (shyness with strangers) is related to the avoidance versus tendency to be assertive in social situations and to meet strangers; the last HA4 sub-scale (fatigability vs. vigor) is related to the avoidance versus tendency to be sthenic and active, recovering quickly from illnesses or stress.

The RD scale consists of four sub-scales and refers to a tendency to the maintenance of behavior in response to cues of social reward. High RD scores stand for being tenderhearted and deeply moved by sentimental appeals, sensitive, dedicated, dependent, and sociable. Adaptive advantages of high RD are the sensitivity to social cues, which facilitates affectionate social relations and genuine care for others, tendency to show emotions easily in presence of others. The disadvantages are related to suggestibility and loss of objectivity frequently present in excessively socially dependent people. The RD1 sub-scale (sentimentality) is related to the tendency versus avoidance to be deeply moved by sentimental appeals, personally experiencing what others are feeling; the $\mathrm{RD} 2$ sub-scale (openness to warm communication) is related to the tendency versus avoidance toward warm social relations, tending to show their emotions easily in presence of others; the RD3 sub-scale (attachment vs. detachment) is related to the tendency versus avoidance to intimacy over privacy; the RD4 sub-scale (dependence vs. independence) is related to the tendency versus avoidance to emotional support and approval from others.

The P scale consists of a single scale and refers to a tendency to the maintenance of behavior despite frustration, fatigue, and intermittent reinforcement. High P scores stand for hard working, perseveration, ambitiousness, and perception of frustration as a personal challenge. Adaptive advantages of high $\mathrm{P}$ are the use of behavioral strategy when rewards are intermittent but contingencies remain stable. The disadvantages are related to perfectionistic perseveration when the contingencies change rapidly.

Conclusively, temperamental traits provide mechanisms to expand the range of stimuli and possibilities, protect one from 
potentially aversive contexts, and supply the appropriate feedback for sculpting the brain and developing interest in specific domains. It has to be noticed that excessive tendency to a specific temperamental trait predicts vulnerability to psychiatric disorders [10]. In particular, high levels of impulsive behaviors, as in high-scored NS subjects, determine increased risk of exhibiting substance abuse and antisocial behavior [11, 12], and conversely, high levels of behavioral inhibition, as in high-scored HA subjects, determine increased risk for developing anxiety disorders and depression [13, 14]. However, apart from individuals with neuropsychiatric symptoms exhibiting scores in personality questionnaires higher than healthy subjects, the temperamental traits are part of nondysfunctional behaviors and contribute to adaptive functioning.

\section{The Neurobiological Bases of Personality Traits}

The variance in the normal range of expression of personality traits appears to be linked to structural variance in specific brain structures. Associations between personality factors and neurobiological measures, as neurotransmitter metabolites $[7,8,15,16]$ and various markers associated with in vivo neuroimaging [17-20], have been demonstrated. Subjects characterized by low striatal dopaminergic receptor density are reported to score lowest on NS and highest on HA [21]. Furthermore, an inverted-U-shaped relation between ratings of the sensation seeking personality linked to NS and measures of striatal dopamine receptor availability has been demonstrated [22].

Neuroanatomical studies indicate that individual differences in personality traits co-vary with brain morphometric parameters, as cortical thickness and gray matter (GM) volume in specific brain regions [23-26]. Neuroimaging studies emphasized the involvement in the personality traits of the cortico-limbic pathways involved also in emotional processing and reappraisal $[18,27,28]$. In particular, NS scores positively correlate with volumes of frontal and posterior cingulate cortices and differences in NS scores are related to the strength of fiber tracts from hippocampus and amygdala to striatum [29]. Furthermore, striatal activity is positively correlated with novelty-based choices [30]. Conversely, HA scores negatively correlate with volumes of orbito-frontal, occipital, and parietal cortices [24] and with the micro-structural integrity of white matter (WM) in cortico-limbic circuitry [31]. Negative relationships between HA and anxiety-related traits and volumes of the entire brain [32] and orbitofrontal [23] and left anterior prefrontal [26] cortices have been also reported. $\mathrm{RD}$ correlates negatively with the volume of the caudate nucleus and frontal gyrus, and $\mathrm{P}$ has a positive association with the volume of the precuneus, paracentral lobule, and parahippocampal gyrus [24].
Furthermore, the personality traits are related to the motivational reactions that imply the involvement of a variety of deep structures concerned in arousal and action [29, 31, 33]. More specifically, increased bilateral caudate and pallidum volumes are associated with higher NS scores, and increased mean diffusivity in the bilateral putamen is associated with higher HA scores [34]. Thus, even macro- and microstructural variations of basal ganglia may contribute to explain the biological variance associated with NS or HA personality phenotype.

\section{Cerebellar Involvement in Personality Traits}

In evidencing the relationships between sub-cortical structures and temperamental traits, it appears evident that the involvement of the cerebellar regions in the personality traits has been almost completely neglected by the most influential authors, and although the cerebellum is a key modulator of behavior, it has not been typically thought of as having a key role in personality. Based on recent data, this paper will review the structural and functional neuroimaging literature that implicates the cerebellum in personality, and will discuss literature data in the context of contemporary theories of affective and cognitive cerebellar function.

\section{Some Clinical Evidence}

Cerebellar networks have been retained to be involved first in motor, and then in cognitive functions [35-38], and more recently also in new domains, as emotional regulation and affective processing [39]. Experimental and clinical research has demonstrated that the cerebellum is implicated in timing and monitoring, integration of somatic and visceral information, spatial and executive functions, and linguistic processing [40-42]. Anatomo-clinical analyses indicate the cerebellum as a critical neuromodulator of intellect and mood and emphasize the posterior vermis, the so-called limbic cerebellum, as involved in the regulation of emotion and affect [39, 43-46].

Magnetic resonance imaging (MRI) studies showed structural or functional cerebellar abnormalities in patients with depression or anxiety [47-49]. There is also a plentiful literature on the possible role of the cerebellar regions in emotional functioning and in aspects of psychopathology, as schizophrenia [50,51], autism [52], attention deficit hyperactive disorder (ADHD) [53], and obsessive-compulsive disorder (OCD) [54]. Even data obtained in healthy subjects indicate reduced capacities of emotional regulation following inhibitory repetitive transcranial magnetic stimulation on the cerebellum [55].

Cognitive, linguistic, and affective deficits as well as personality changes are reported in subjects with lesions of the cerebellar posterior lobe and vermis (the cerebellar cognitiveaffective syndrome described by Schmahmann) [35]. The core 
features of this syndrome consist of executive dysfunctions (such as disturbances in planning, set-shifting, abstract reasoning, and working memory), visuo-spatial deficits, language symptoms (including agrammatism and anomia), and behavioral-affective disturbances, consisting of blunting of affect or disinhibited and inappropriate behavior [35].

Actually, the psychopathological profile of patients affected by cerebellar diseases of different etiology describes them as impulsive, obsessive, hyperactive, disinhibited, and with ruminative and stereotypical behaviors, features affecting their personality style [37]. These clinical observations, however detailed they may be, do not take into account any cerebellar involvement in personality traits.

\section{Cerebellar Involvement in Novelty Seeking and Harm Avoidance Traits}

Since the several personality indices are rooted in behavior and have a strong action component, the link between cerebellum and personality traits appears intriguing [56-58]. The positive association between pattern of cerebellar synchronous neuronal activity (indexed by regional homogeneity) and extraversion (personality dimension described by Eysenck and essentially similar to NS) supports the hypothesis that the cerebellum is involved in increasing the hedonic tone of extraverts [59]. Furthermore, perfusion indices in the cerebellum correlates positively with NS scores and negatively with HA scores [60]. Assuming that variability in temperamental traits is normally distributed, we recently performed a correlational region of interest (ROI)-based study between TCI scores and cerebellar volumes on a large sample of healthy subjects of both sexes and different ages [56]. The exclusion of subjects with neuropsychiatric disorders minimized the influence of state-dependent phenomena associated with pathological conditions and environmental confounders. Cerebellar volumes of WM and cortex of right and left hemispheres correlated positively with NS scores and negatively with HA scores. No relationship between cerebellar volumes and the other two TCI scales (RD and P) was found (Fig. 1).

Since the ROI-based approach prevented a detailed and yet crucial localization of the cerebellar regions involved in personality traits, a subsequent voxel-based morphometry (VBM) analysis with a diffusion tensor imaging (DTI) scan protocol was performed on cerebellar macro- and microstructural organization [57]. The VBM approach revealed positive associations between NS scores and volumes of the vermian lobules VIIb, VIII, and Crus 2. It is important to emphasize that the posterior vermis (lobules VI, VII, VIII, and Crus 1 and 2) is mostly involved in the regulation of emotion and affect, and in higher-level cognitive processes [45], due its well-known projections to the area 46 in dorsolateral prefrontal cortex [61].
An interesting relationship between NS scores and cerebellar areas was found also at micro-structural level, as indicated by DTI (mean diffusivity, MD; and fractional anisotropy, FA) data. NS scores associated positively with FA measures of WM in lobules IV-V, VI, and IX, and negatively with MD of GM measures in lobules IV-V, VI, VIII, IX, and Crus 1 and 2. No relationship between cerebellar volumes and the other TCI scales was found. Notably, in healthy subjects, a triad including increased volumes, decreased MD, and increased FA indicates high integrity and efficiency, and advanced organization of the neuronal structures. Thus, the increased cerebellar GM volumes, the increased WM FA, and the decreased GM MD associated with high NS scores emphasize that macro- and micro-structural features of posterior vermis support the behaviors related to seeking for novelty.

Essentially, regardless of the methodology used (ROIbased or voxel-based analyses), our findings evidenced increased cerebellar volumes related to NS, and decreased cerebellar volumes related to HA.

\section{Why Is the Cerebellum Related to Personality Traits?}

The correlations positive between cerebellar volumes and NS scores and negative between cerebellar volumes and HA scores appear fully consistent with the different engagements that subjects with different styles of personality require to their cerebellar circuitries. A subject who willingly searches for new situations, explores new environments, freely takes the risk, is sensation and reward seeking, and lacks inhibition, as novelty seekers do, needs very rapid detection of unfamiliar events, flexible switching among alternatives and contexts, and fast adaptation to continuously changing environment. All these functions require heavy engagement of the cerebellum. Whether "larger is more powerful," the high requests a seeker subject makes to his/her cerebellum could enlarge it, and vice versa, the low requests an avoiding subject makes to his/her cerebellum could reduce it. However, it is far to be clarified whether the temperamental traits determine the size of brain regions or conversely, the differently sized brain regions determine the temperamental traits. Future studies will help to clarify which comes first. Furthermore, it is well known that the development of the neural organization is influenced by genetic predispositions and environmental events, as well as by neuroplastic responses to experiences, determining how neurons are connected and how they communicate within and across neural pathways. However, how the genetic, epigenetic, and environmental variables may together develop and sustain the temperamental individual differences remains to be clarified. 

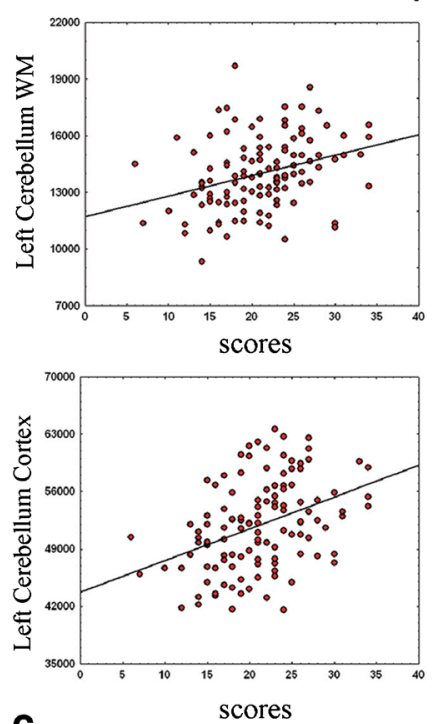

C

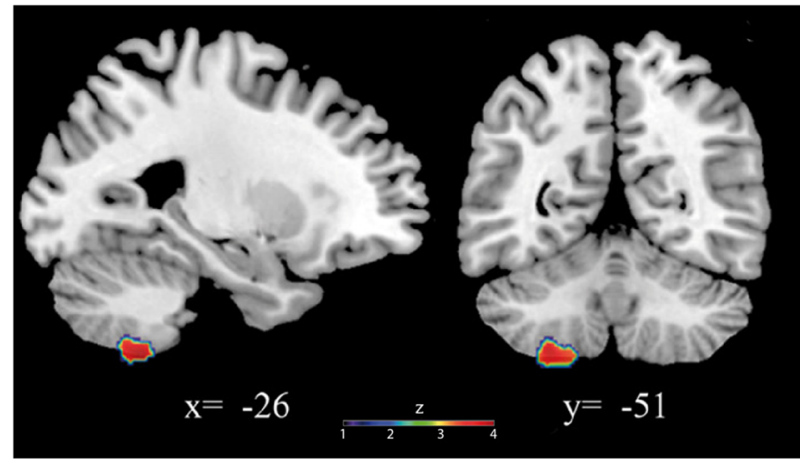

Fig. 1 Cerebellar volumes and TCI scores. Scatterplots are separated for novelty seeking (a) and harm avoidance (b) scores in relation to cerebellar white matter (WM) and cortex volumes. Linear fit (solid black line) are also reported. In (c), the positive association between cerebellar gray matter volumes and novelty seeking scores is represented. Coordinates are in Montreal Neurological Institute (MNI) space. $Z$ above color bar

\section{Cerebellar Involvement in Managing Novelty}

It is widely accepted that the cerebellar activity signals when sensory input differs from memory-driven expectations and provides a sensory prediction error. In accordance with the cerebellar novelty/error detection function, in the cerebellum, forward and inverse internal models are formed to adapt motor and cognitive activities to contextual information [62]. The internal model hypothesis for the control of novelty-related mental activities considers that the mismatch between the mental generated solution and the new incoming information would activate the brain novelty system. Such a system consists of the hippocampal CA1 area and midbrain dopaminergic neurons in the ventral tegmental area (VTA) [63]. This circuit is activated when the CA1 area detects new information. The resulting novelty signal is sent (through the ventral striatum) to the VTA neurons which then fire in response to novelty [64]. The novelty system in turn would activate the attentional

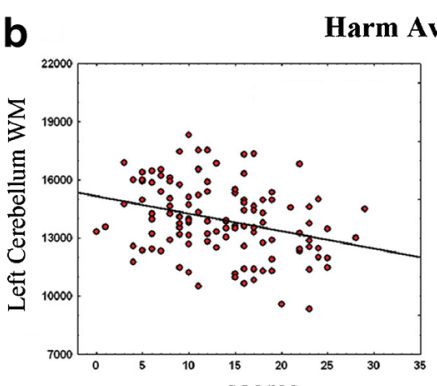

Harm Avoidance
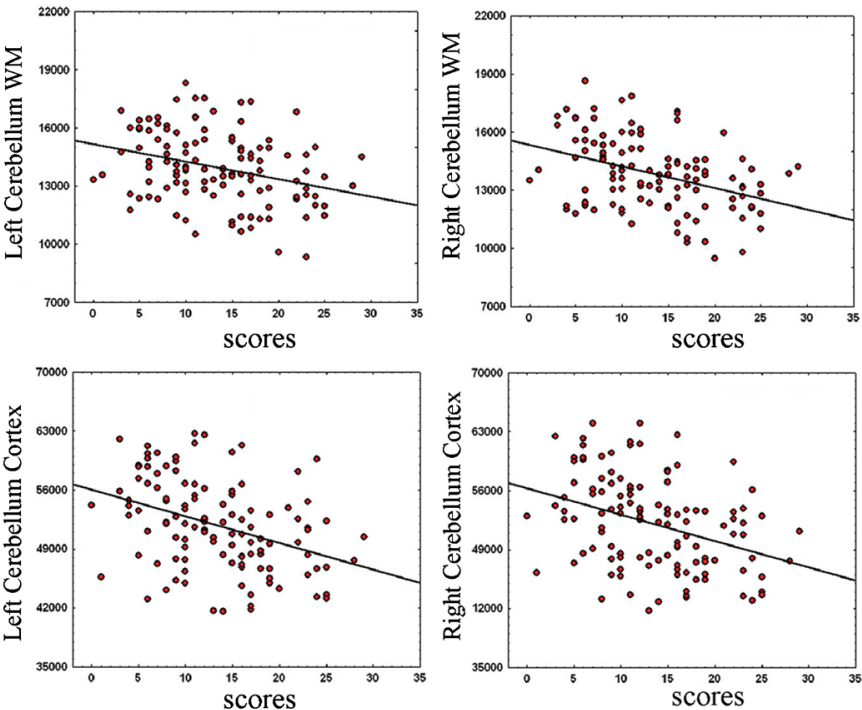

\section{Novelty Seeking}

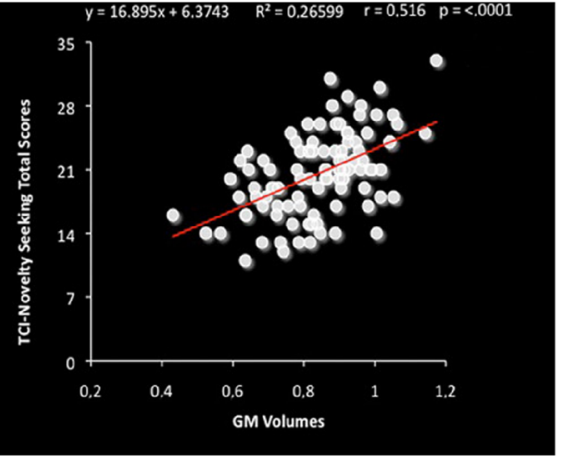

indicates normalized $t$ values. In figures, left is left. Areas significantly associated with novelty seeking scores in the voxel-based analyses were used as regions of interest (ROI) to extract raw data and create scatterplot. Equation, $R^{2}, r$, and $p$ values, as well as linear fit (solid red line), are also reported (color figure online)

system during the explicit phase of novelty-related thought [65]. Since usually no correct solution to a new problem is derived during the explicit phase, an implicit novelty-related phase is performed by tuning the internal models encoded in the cerebellar circuitries. In triggering the new mental activities, the cerebellum could alarm the prefrontal cortex about the absence of internal models matching the novel information, maintain the newly generated internal models, and incorporate them into routine schemes of thought. To successfully manage novelty, the co-activation of cerebellum and neocortical or sub-cortical (basal ganglia) areas is thus needed. Timing, predictive, and learning properties of the cerebellum, once integrated with the properties of the neocortical, basal ganglia, and limbic circuits [66-69], may be valid for supporting the cerebellar involvement in recognition of and seeking for novelty [70].

Perceiving the sameness of events and contexts and emitting automatic responses as reply to familiar information on 
one hand enhances efficiency and reliability of the system, but on the other hand, it promotes premature closure, perseveration, and response rigidity. As Mesulam stated [71], "CNS has compensated for these limitations by developing specialized neural circuits for the rapid detection of unfamiliar events." In this sense, by loosening the rigid stimulus-response linkages, the novelty seeking behaviors in which the cerebellum is involved represent an advanced antithesis to the pursuit of sameness and endow the organism with rapid change and adaptive response.

\section{Cerebellar Involvement in Managing Explorativity}

Consistently with its tendency to detection of and search for novelty, NS trait is characterized by a clear tendency to an enhanced explorativity that results in coming across events. Thus, the discovery of a new stimulus reinforces further exploration and detection of novelty. Thus, explorativity and recognition of and seeking for novelty appear closely related behaviors. By requiring close integration between environmental (sensory) information and searching (motor) acts, the explorative functions mimic the sensorimotor role classically attributed to cerebellar networks. Animal and human findings indicate that cerebellum is involved in exploring environments and responding to novel stimuli $[72,73]$. There is now plenty of evidence that cerebellar bidirectional interconnections with cortical and sub-cortical regions $[66,68,72$, 74-76] play a role in active exploration. Cerebellar lesions elicit deficits in representing the environment, due to inappropriate explorative pattern [77, 78], and they impair mental folding and manipulation of tridimensional stimuli [79]. Mutant mice with vermian hypoplasia exhibit reduced tendency to explore objects or environments and increased tendency to perseveratively move about $[80,81]$. Furthermore, the altered exploration exhibited by autistic children and subjects affected by Williams syndrome has been linked to their cerebellar structural or neurochemical alterations [76, 82-84]. The involvement of cerebellar regions in explorative tendencies that characterize NS trait is consistent with the finding showing high scores in the exploratory excitability (NS1 sub-scale) related with high FA and low MD in cerebellar lobules IV, $\mathrm{V}$, and VI [57].

\section{Cerebellar Involvement in Managing Motivation}

The incentive motivational system mediates a general form of appetitive eagerness as well as a variety of addictions, from drug to sex, and from shopping to social bonding [85]. The cerebellum and basal ganglia and their reciprocal connections have complementary roles in facilitating motivation that sustains and reinforces these behaviors [66, 67, 86-89]. Growing evidence implicates the cerebellum as an intermediary between motor and reward control systems, as well as between motivational and cognitive control systems, and suggests that the cerebellum may be intertwined with brain processes related to reward, motivational drive, saliency, inhibitory control, and insight. Recent findings indicate that the cerebellum may modulate the flow of aversive information and motivational processing [90]. Thus, to successfully manage reward- and motivation-related behaviors, the cerebellum and neocortical/sub-cortical areas must be co-activated. Once more, cerebellar functionality when integrated in the circuits that are formed with the neocortex, basal ganglia, and limbic system could affect the control of motivational functions [70].

\section{Cerebellar Involvement in Managing Anxiety-Related Behaviors}

HA trait encompasses anticipatory worry, fear of uncertainty, shyness, and fatigability. Anticipatory anxiety that is characterized by worry about future events has many of the characteristics of generalized anxiety, as increase of attention, apprehension, restlessness, and avoidance [91]. Conditions with a component of anticipatory anxiety include panic, social phobia, public speaking, and generalized anxiety. While in healthy individuals during anticipatory anxiety the increased perfusion of cingulate, insula, temporal, prefrontal, and orbitofrontal cortices is accompanied by increased perfusion of cerebellar and thalamic areas [92-94], in individuals with social phobia, the enhanced cerebral blood flow in the cortical regions is associated with reduced bilateral cerebellar blood flow [95].

Even the uncertainty of occurrence, timing, and intensity of aversive events may lead to increased anticipatory anxiety. Recently, the neural mechanisms of the uncertainty in the anticipation of an aversive event, as uncomfortable rectal distension, have been investigated by using functional MRI [96]. Findings revealed that uncertain anticipation of the aversive event elicits a clear de-activation of cerebellar regions accompanied by activation of cingulate and prefrontal cortices.

HA trait integrates the shyness, core temperamental dimension that describes the feeling of apprehension and discomfort, especially in response to new situations or unfamiliar people. Stronger forms of shyness are usually referred to as social anxiety or social phobia. Shy individuals tend to internalize their problems, or dwell on their problems internally instead of expressing their concerns, which leads to disorders like depression and anxiety. An emerging body of studies has attempted to identify the biological bases of shyness. Recently, it has been reported that, in healthy subjects, the shyness scores positively correlate with GM density in the left cerebellar posterior lobe and right superior temporal gyrus [97]. Furthermore, significant positive correlations between shyness scores and functional connectivity have been found for left cerebellar posterior lobe [97]. 


\section{Cerebellar Involvement in Maladaptive Behaviors}

Although personality traits contribute to adaptive functioning, excessive and inflexible behavioral tendencies lead to maladaptive patterns of behavior and to disruption of internal homeostasis by which the organism seeks to regulate its internal environment. Personality disorders have been reported to be a combination of extreme temperamental and immature character expressions [20, 23]. As Cloninger [7] posited, high NS scores are linked to antisocial, borderline, narcissistic, and histrionic personality disorders that share high levels of impulsivity, while high HA scores are linked to avoidant, dependent, and obsessive-compulsive personality disorders that share high levels of anxiety. Thus, extreme levels of NS or HA characterize many neuropsychiatric conditions, as ADHD, bipolar mania, drug or alcohol addiction, schizophrenia, and anxiety-related disorders [98-100]. The cerebellum is involved in anxiety-related symptoms, such as hyper-arousal present in post-traumatic stress disorders (PTSDs) and other anxiety disorders [101]. Moreover, the cerebellar hyperactivity is reduced by fluoxetine [102]. Adults affected by PTSD exhibit increased blood flow in the cerebellum [103]. Similarly, cerebellar abnormalities are observed in patients with OCD and ADHD [104, 105]. Recently, it has been reported that PTSD individuals show reduced cerebellar GM volumes in comparison to OCD individuals [106]. The fronto-cerebellar and basal ganglia-cerebellar connections may represent the biological substrates for such pathological conditions [107].

Morphological and functional studies on subjects with compulsive drug abuse prominently indicate that the cerebellum plays a modulatory role in processing reward and stimulus salience [108], probably linked to its reciprocal connections with dopaminergic networks in the basal ganglia [109], as well as a significant role in executive control, drug craving, and response selection, probably linked to its reciprocal connections with cortical structures [110-113]. Although in users of addictive substances GM volumes in bilateral cerebellum are reported to be smaller than in controls as a consequence of the chronic drug use [108, 114], increased cerebellar vermis activation during reward-related tasks has been reported [115]. The cerebellar vermis participates both in attentional processes linked to motor responses [116] and in context-dependent changes in sensorimotor sets to facilitate motor outputs [117]. These capacities are important in drug dependence since a hyper-attentive state with regard to salient drug-related stimuli may underlie drug craving and relapse [118]. Notably, the vermis activation in response to cocaine-related cues indicates its involvement in hyper-attentive states. In addiction disorders, in which the frontal lobes are compromised [110], the cerebellar activity increases in an attempt of supporting frontal lobe function. These observations support the vermis central role in organizing sensory inputs and planning motor responses to rewarding and incentive-related stimuli.
Interestingly, its role in modulating these responses appears to increase when the frontal lobes are compromised by disease or chronic drug use.

A recent study also described reduced cerebellar volume in binge-drinking adolescents, related to recent alcohol consumption [119], and complementing finding provided evidence for binge-drinking-related effects on cerebellar reward response [85], working memory [120], verbal encoding [120, 121], and affective decision-making [122]. Interestingly, reduced response to reward in binge drinkers was localized to lobule VIIa/Crus I [85]. Crus I has been shown to be functionally connected to brain regions involved in emotional salience, such as the anterior insula and anterior cingulate cortex (ACC) [123], which provides further evidence for posterior cerebellar involvement with addiction [108].

Thus, it is teasing to advance that the looped corticostriatal-cerebellar-thalamic-cortical circuit critically sustains the processes linked to temperamental individual differences. Although it is generally assumed that frontal lobes underlie several features of personality, a re-thinking of the way the cerebellum interacts with cerebral cortex and the kind of operations it handles appears needed. Cerebellum with its complex modular architecture for adaptively controlling motor, cognitive, and emotional material could play a comparable role in facilitating motivation that sustains and reinforces temperamental features. The model that is emerging (but needs to be refined) may explain how the ability to form intentions and to bring them to fruition results in building normal or abnormal personality traits.

\section{The Cerebellar Volumes in Alexithymic Traits}

The cerebellar contribution in some personality traits and emotional processing has led to investigate the cerebellar involvement even in alexithymia, a construct of personality characterized by impairment in cognitive, emotional, and affective processing. The term alexithymia coined by the psychotherapist Peter Sifneos comes from the Greek words lexis (speech) and thumos (soul, emotion), modified by an alpha privative, and literally means "no words for emotions" [124]. It describes people with deficiencies in identifying, processing, or describing subjective feelings or emotional aspects of social interaction, difficulty in distinguishing between feelings and bodily sensations of emotional arousal, and limited affect-related fantasy and imagery [125-127].

Alexithymia is not a psychological disorder in itself, but it is a personality construct present in a broad spectrum of psychiatric and psychosomatic disorders, as chronic pain, somatoform disorders, addictive disorders, anxiety, and depression [128-133]. Neuroimaging studies have indicated that people with high alexithymic traits show structural and functional alterations in brain areas associated with emotional awareness, as ACC, 
fusiform gyrus, amygdala, parahippocampal gyrus, and insula [134-137]. Although altered cerebellar activity was reported in the presence of alexithymia [136, 138], the new conceptualization of the limbic cerebellum did not consider these reports. And yet, the altered cognitive experience of emotion featuring the alexithymic traits is associated with some cerebellar volumetric alterations. We recently described the positive association between alexithymia scores (measured by the 20-item Toronto Alexithymia Scale, TAS-20) and cerebellar GM volumes in right and left Crus 1 (Fig. 2) [139]. No micro-structural variation in Crus 1 as well as in other cerebellar areas was related with alexithymic traits.

Crus 1 and lobule VI constitute a node in the corticolimbic network centered on the dorsal ACC and frontoinsular cortex, and they are involved in detecting, integrating, and filtering emotional information [67, 112, 140]. Furthermore, aversive stimuli (noxious heat, unpleasant images) and negative emotional faces produce increased activation in Crus 1 and lobule VI $[90,141]$. Even the act of identifying emotional intonation (affective prosody) produces activation in Crus 1 and lobules VI and VII [142, 143]. Once again, a straightforward question is how the structure relates to function in the brain. Since training on particular tasks or experiencing complex environment does increase the volume of the brain structures related to specific functions, it seems reasonable to assume that volume positively co-varies with function [144-147]. Volumes in bilateral Crus 1 were positively related to TAS-20 scores that in turn were negatively related to volumes of some limbic and para-limbic structures. These results are closely consistent with the negative correlation between the activation of Crus 1 and lobules VI and VIIb and the activation of limbic and paralimbic areas described by Moulton et al. [90], and they suggest a possible functional modality for the cerebellar involvement in emotional processing [148-150]. The increased volumes of Crus 1 could result in an enhanced inhibitory output of Purkinje cells on the deep cerebellar nuclei, modulating thus their excitatory projection to the extra-cerebellar targets including the limbic system [68]. Thus, the inhibition of nuclear activity could result in reduced excitatory input to limbic and para-limbic structures that in turn could undergo a volumetric reduction because of the diminished activation level. Interestingly, smaller ACC volumes and greater posterior cerebellar volumes have been reported in patients with Cushing's disease or obsessivecompulsive disorder featured by depressive and anxiety symptoms as well as cognitive, affective, and personality disorders [151, 152]. These structural findings nicely fit functional data that report in people with high alexithymic traits reduced neural response to emotional stimuli in the limbic system and in contrast increased neural response to stimuli closely associated with physical information in somato-sensory and sensorimotor areas [135].

\section{The Embodied Emotion in Cerebellum}

It has been advanced that the neocortical (prefrontal/posterior parietal)-cerebellar connections may represent the anatomical substrate for the executive functions and sensorimotor interaction $[153,154]$. In addressing the role of sub-cortical structures in the procedural and declarative knowledge and representational abilities, Koziol et al. [153] embraces an implicit, bottom-up model based on a continuous sensorimotor interaction with the environment. According to this model, the procedural (implicit) and declarative (explicit) knowledge is explained in terms of continuous "on-line" sensorimotor anticipation and "off-line" simulation of (imagination or thinking about) action. The cerebellum crucially teaches neocortical systems how to anticipate the action by "thinking" about outcomes or sensory feedback [45].

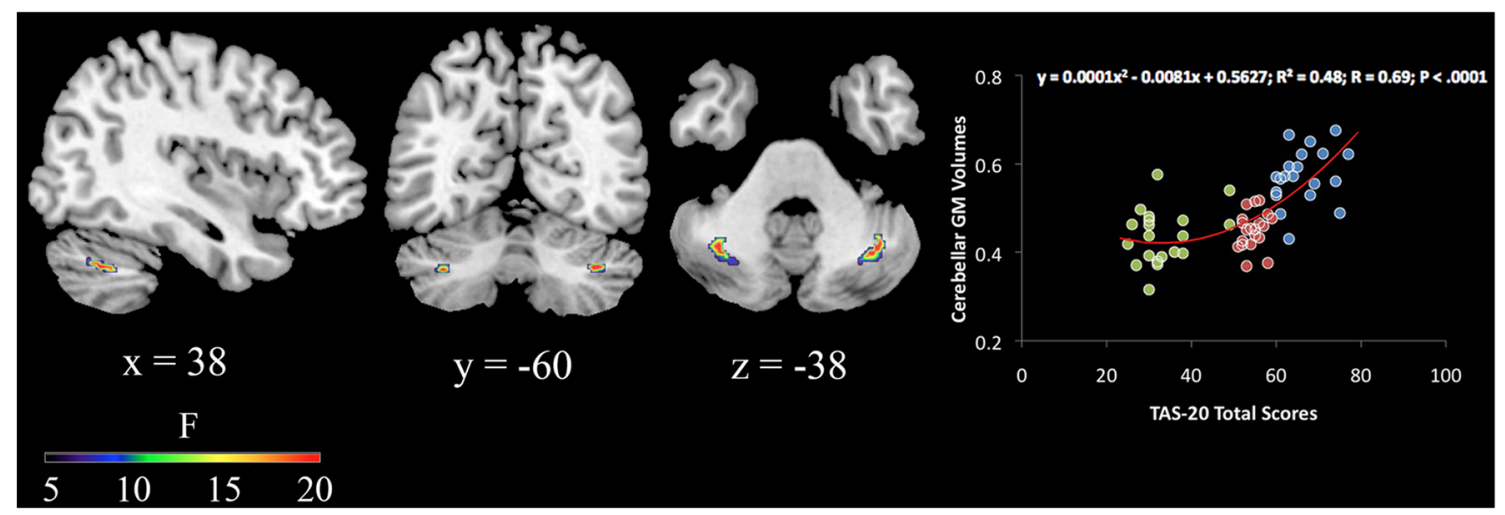

Fig. 2 Cerebellar gray matter correlates of alexithymia. Individuals with high alexithymic traits (TAS-20 scores $\geq 61$ ) showed greater volumes in bilateral Crus 1 than the individuals with middle (TAS-20 scores 51-60) or low (TAS-20 scores $\leq 50$ ) alexithymic traits. Above color bar, F values are indicated. Bilateral volumes in Crus 1 associated with TAS-20 scores were used as regions of interest (ROI) to extract raw data and create scatterplot, where equation, $R^{2}, r$, and $p$ value, as well as quadratic fit (solid red line) are reported. Coordinates are in MNI space (color figure online) 
Following Schmahmann's suggestion [155], it seems appropriate to add to the neocortico-cerebellar circuits a limbiccerebellar limb that should represent an additional anatomical substrate for emotional processing. Following Ito's proposal on internal models [62], the cerebellum performs the same operational processing on information linked to both movement and thought. It is intriguing to propose that the cerebellum may perform such operations even on emotional information. Motor, cognitive, and emotional data could be all encoded in a common sensorimotor format that could form an "embodied" representation of the internal and external environment. This representation in turn may be internally manipulated before (on-line) or instead of (off-line) acting directly on environment [70, 156-158]. Since the original work of Varela et al. [159], the concept of embodiment has become a key paradigm of interdisciplinary approaches, from philosophy to psychology, and from psychiatry to neuroscience [160-163]. The embodiment refers not only to embedding motor, cognitive, and emotional processes in a brain circuitry but also to considering a common sensorimotor format as the basis of all these processes. To reach conscious awareness, the sensorimotor code has to be translated by the neocortical areas. In the condition of efficient functioning, the subject has internal models of internal or external environment that form embodied representations grounded in sensorimotor control loops. In other words, sensorimotor information (closely related to Damasio's concept of the "somatic markers" [164] and to Fuchs and Koch's proposal of "bodily resonance" [165]) normally functions as the interoceptive and proprioceptive feedback of the emotional experience. This involves the activation of the limbic hippocampal and amygdaloid system that in turn sends signals to cerebellum via subcortical pathways passing through the striatum and the ventral tegmental area. Thus, to successfully manage emotionality, a joint action of cerebellum and neocortical/sub-cortical areas appears then needed. Once again, the typical properties of the cerebellum, integrated within the neocortex, basal ganglia, and limbic system circuits, could lead to the control of complex emotion-related functions [70].

In the presence of alexithymia, the bodily reactions seem unrelated to emotional affordances of a given situation, which means that the bodily signals could keep "trapped" into sensorimotor format (in the cerebellum?) and not translated in conscious emotional awareness (by the neocortical areas). Not by chance, alexithymic traits are particularly frequent in patients with somatoform disorders who have often problems to relate sensorimotor information to corresponding emotional situations, leading to detached feelings of pressure, burning, and pain, which are then attributed to assumed somatic illnesses [166]. It is reasonable to advance that, in highly alexithymic subjects, the cerebellar action that traps the emotional information in its sensorimotor format might affect both on-line and off-line elaboration processes. Interestingly, these subjects exhibit not only deficiency in distinguishing between feelings and bodily sensations of emotional arousal (on-line processing) but also limited emotionality related to fantasy and imagery (off-line processing), exhibiting a concrete and reality-based cognitive style rather than capacities of symbolization, vivid fantasies, and imaginative activities [128].

It is possible to perform a further step in the conceptualization of cerebellar functionality in the embodiment processes by integrating the model by Ito [62], the recent literature on embodied cognition [153, 167-169] and our own results [139]. We suggest that the cerebellum may be the site not only of the implicit thought but also of the implicit emotion. On such a basis, a network comprising cerebellum, limbic system, and somato-sensory, sensorimotor, and prefrontal cortices could be involved in sensing the physiological bodily conditions [151], representing the interoceptive and proprioceptive feedback within the context of ongoing activities [152] and feeling self-induced and externally induced emotions [170]. Thus, in subjects with high alexithymic traits, the enlarged volumes in Crus 1 would be associated to a lacking translation (from the sensorimotor format to the conscious symbolic representation) of the emotional signals that thus remain noncognitively described, and not mentalized. On this vein, alexithymia, first seen as equivalent of emotional blindsight and then of emotional agnosia [171], may be considered a deficit in the embodiment process characterized by a disturbance in translating presymbolic bodily signals in symbolic emotional awareness [70, 156-158, 172, 173].

\section{Compliance with ethical standards}

Conflict of interest The authors declare that they have no conflict of interest.

\section{References}

1. Weiner IB, Tennen HA, Suls JM. Personality and social psychology, handbook of psychology. 2nd ed. USA: John Wiley \& Sons; 2013.

2. American Psychiatric Association. Diagnostic and statistical manual of mental disorders. 4th ed. Washington: American Psychiatric Association; 2000.

3. Eysenck HJ, Eysenck MW. Personality and individual differences: a natural science approach. New York: Plenum; 1985.

4. Gray JA. The neuropsychology of anxiety: an enquiry into the functions of the septo-hippocampal system. 1st ed. Oxford: Oxford University Press; 1982.

5. Watson D, Wiese D, Vaidya J, Tellegen A. The two general activation systems of affect: structural evolutionary considerations, and psychobiological evidence. J Person Soc Psychol. 1999;76: 820-38.

6. Costa PT, McCrae RR. Normal personality assessment in clinical practice: the NEO personality inventory. Psych Assess. 1992;4:513. 
7. Cloninger CR. A systematic method for clinical description and classification of personality variants. Arch Gen Psychiatry. 1987;44:573-88.

8. Cloninger CR, Svrakic DM, Przybeck TR. A psychobiological model of temperament and character. Arch Gen Psychiatry. 1993;50:975-90.

9. Comings DE, Gade-Andavolu R, Gonzalez N, Wu S, Muhleman $\mathrm{D}$, Blake $\mathrm{H}$, et al. A multivariate analysis of 59 candidate genes in personality traits: the temperament and character inventory. Clin Genet. 2000;58:375-85.

10. Richter J, Brändström S. Personality disorder diagnosis by means of the temperament and character inventory. Compr Psychiatry. 2009;50:347-52.

11. Meyer B, Johnson SL, Carver CS. Exploring behavioral activation and inhibition sensitivities among college students at risk for bipolar spectrum symptomatology. J Psychopathol Behav Assess. 1999;21:275-92.

12. Mitchell JT, Nelson-Gray RO. Attention-deficit/hyperactivity disorder symptoms in adults: relationship to Gray's behavioral approach system. Personal Individ Differ. 2006;40:749-60.

13. Biederman J, Hirshfeld-Becker DR, Rosenbaum JF, Herot C, Friedman D, Snidman N, et al. Further evidence of association between behavioral inhibition and social anxiety in children. Am J Psychiatry. 2001;158:1673-9.

14. Muris P, Merckelbach H, Schmidt H, Gadet BB, Bogie N. Anxiety and depression as correlates of self-reported behavioural inhibition in normal adolescents. Behav Res Ther. 2001;39:1051-61.

15. Kim MS, Cho SS, Kang KW, Hwang JL, Kwon JS. Electrophysiological correlates of personality dimensions measured by temperament and character inventory. Psychiatry Clin Neurosci. 2002;56:631-5.

16. Limson R, Goldman D, Roy A, Lamparski D, Ravitz B, Adinoff $\mathrm{B}$, et al. Personality and cerebrospinal fluid monoamine metabolites in alcoholics and controls. Arch Gen Psychiatry. 1991;48: 437-41.

17. Canli T, Zhao Z, Desmond JE, Kang E, Gross J, Gabrieli JD. An fMRI study of personality influences on brain reactivity to emotional stimuli. Behav Neurosci. 2001;115:33-42.

18. Kumari V, Ffytche DH, Williams SC, Gray JA. Personality predicts brain responses to cognitive demands. J Neurosci. 2004;24: 10636-41.

19. Sugiura M, Kawashima R, Nakagawa M, Okada K, Sato T, Goto $\mathrm{R}$, et al. Correlation between human personality and neural activity incerebral cortex. Neuroimage. 2000;11:541-6.

20. Youn T, Lyoo IK, Kim JK, Park HJ, Ha KS, Lee DS, et al. Relationship between personality trait and regional cerebral glucose metabolism assessed with positron emissiontomography. Biol Psychol. 2002;60:109-20.

21. Montag C, Markett S, Basten U, Stelzel C, Fiebach C, Canli T, et al. Epistasis of the DRD2/ANKK1 TaqIa and the BDNFVal66Met polymorphism impacts novelty seeking and harm avoidance. Neuropsychopharmacology. 2010;35:1860-7.

22. Gjedde A, Kumakura Y, Cumming P, Linnet J, Møller A. InvertedU-shaped correlation between dopamine receptor availability in striatum and sensation seeking. Proc Natl Acad Sci U S A. 2010;107:3870-5.

23. DeYoung CG, Hirsh JB, Shane MS, Papademetris X, Rajeevan N, Gray JR. Testing predictions from personality neuroscience. Brain structure and the big five. Psychol Sci. 2010;21:820-8.

24. Gardini S, Cloninger CR, Venneri A. Individual differences inpersonality traits reflect structural variance in specific brain regions. Brain Res Bull. 2009;79:265-70.

25. $\mathrm{Hu}$ X, Erb M, Ackermann H, Martin JA, Grodd W, Reiterer SM. Voxel based morphometry studies of personality: issue of statistical model specification-effect of nuisance covariates. Neuroimage. 2011;54:1994-2005.
26. Yamasue $\mathrm{H}$, Abe $\mathrm{O}$, Suga $\mathrm{M}$, Yamada $\mathrm{H}$, Inoue $\mathrm{H}$, Tochigi $\mathrm{M}$, et al. Gender-common and specific neuroanatomical basis of human anxiety-related personality traits. Cereb Cortex. 2008;18:46-52.

27. Deckersbach T, Dougherty DD, Rauch SL. Functional imaging of mood and anxiety disorders. J Neuroimaging. 2006;16:1-10.

28. Gogtay N, Sporn A, Clasen LS, Nugent III TF, Greenstein D, Nicolson R, et al. Comparison of progressive cortical gray matter loss in childhood-onset schizophrenia with that in childhood-onset atypical psychoses. Arch Gen Psychiatry. 2004;61:17-22.

29. Cohen MX, Schoene-Bake JC, Elger CE, Weber B. Connectivitybased segregation of the human striatum predicts personality characteristics. Nat Neurosci. 2009;12:32-4.

30. Wittmann BC, Daw ND, Seymour B, Dolan RJ. Striatal activity underlies novelty-based choice in humans. Neuron. 2008;58:96773 .

31. Westlye LT, Bjørnebekk A, Grydeland H, Fjell AM, Walhovd KB. Linking an anxiety-related personality trait to brain white matter microstructure: diffusion tensor imaging and harm avoidance. Arch Gen Psychiatry. 2011;68:369-77.

32. Knutson B, Momenan R, Rawlings RR, Fong GW, Hommer D. Negative association of neuroticism with brain volume ratio in healthy humans. Biol Psychiatry. 2001;50:685-90.

33. LeDoux J. Rethinking the emotional brain. Neuron. 2012;73:65376.

34. Laricchiuta D, Petrosini L, Piras F, Cutuli D, Macci E, Picerni E, et al. Linking novelty seeking and harm avoidance personality traits to basal ganglia: volumetry and mean diffusivity. Brain Struct Funct. 2014;219:793-803.

35. Schmahmann JD, Sherman JC. The cerebellar cognitive affective syndrome. Brain. 1998;121:561-79.

36. Paradiso S, Johnson DL, Andreasen NC, O'Leary DS, Watkins GL, Ponto LL, et al. Cerebral blood flow changes associated with attribution of emotional valence to pleasant, unpleasant, and neutral visual stimuli in a PET study of normal subjects. Am J Psychiatry. 1999;156:1618-29.

37. Schmahmann JD, Weilburg JB, Sherman JC. The neuropsychiatry of the cerebellum-insights from the clinic. Cerebellum. 2007;6: 254-67.

38. Timmann D, Daum I. Cerebellar contributions to cognitive functions: a progress report after two decades of research. Cerebellum. 2007;6:159-62.

39. Schmahmann JD. Disorders of the cerebellum: ataxia, dysmetria of thought, and the cerebellar cognitive affective syndrome. J Neuropsychiatry Clin Neurosci. 2004;16:367-78.

40. Ivry RB, Spencer RM. The neural representation of time. Curr Opin Neurobiol. 2004;14:225-32.

41. Zhu JN, Yung WH, Kwok-Chong Chow B, Chan YS, Wang JJ. The cerebellar-hypothalamic circuits: potential pathways underlying cerebellar involvement in somatic-visceral integration. Brain Res Rev. 2006;52:93-106.

42. De Smet HJ, Paquier P, Verhoeven J, Mariën P. The cerebellum: its role in language and related cognitive and affective functions. Brain Lang. 2013;127:334-42.

43. Schmahmann JD. An emerging concept. The cerebellar contribution to higher function. Arch Neurol. 1991;48:1178-87.

44. Schmahmann JD. From movement to thought: anatomic substrates of the cerebellar contribution to cognitive processing. Hum Brain Mapp. 1996;4:174-98.

45. Stoodley CJ, Schmahmann JD. Evidence for topographic organization in the cerebellum of motor control versus cognitive and affective processing. Cortex. 2010;46:831-44.

46. Stoodley CJ, Valera EM, Schmahmann JD. Functional topography of the cerebellum for motor and cognitive tasks: an fMRI study. Neuroimage. 2012;59:1560-70. 
47. Fitzgerald PB, Laird AR, Maller J, Daskalakis ZJ. A meta-analytic study of changes in brain activation in depression. Hum Brain Mapp. 2008;29:683-95.

48. Liu Z, Xu C, Xu Y, Wang Y, Zhao B, Lv Y, et al. Decreased regional homogeneity in insula and cerebellum: a resting state fMRI study in patients with major depression and subjects at high risk for major depression. Psychiatry Res. 2010;182:211-5.

49. De Bellis MD, Kuchibhatla M. Cerebellar volumes in pediatric maltreatment-related posttraumatic stress disorder. Biol Psychiatry. 2006;60:697-703.

50. Mothersill O, Knee-Zaska C, Donohoe G. Emotion and theory of mind in schizophrenia-investigating the role of the cerebellum. Cerebellum; 2015

51. Shinn AK, Baker JT, Lewandowski KE, Öngür D, Cohen BM. Aberrant cerebellar connectivity in motor and association networks in schizophrenia. Front Hum Neurosci. 2015;9:134.

52. Wang SS, Kloth AD, Badura A. The cerebellum, sensitive periods, and autism. Neuron. 2014;83:518-32.

53. Ivanov I, Murrough JW, Bansal R, Hao X, Peterson BS. Cerebellar morphology and the effects of stimulant medications in youths with attention deficit-hyperactivity disorder. Neuropsychopharmacology. 2014;39:718-26.

54. Eng GK, Sim K, Chen SH. Meta-analytic investigations of structural grey matter, executive domain-related functional activations, and white matter diffusivity in obsessive compulsive disorder: an integrative review. Neurosci Biobehav Rev. 2015;52:233-57.

55. Schutter DJ, van Honk J. The cerebellum in emotion regulation: a repetitive transcranial magnetic stimulation study. Cerebellum. 2009;8:28-34.

56. Laricchiuta D, Petrosini L, Piras F, Macci E, Cutuli D, Chiapponi $\mathrm{C}$, et al. Linking novelty seeking and harm avoidance personality traits to cerebellar volumes. Hum Brain Mapp. 2014;35:285-96.

57. Picerni E, Petrosini L, Piras F, Laricchiuta D, Cutuli D, Chiapponi $\mathrm{C}$, et al. New evidence for the cerebellar involvement in personality traits. Front Behav Neurosci. 2013;7:133.

58. Schutter DJLG, Koolschijn PCMP, Peper JS, Crone EA. The cerebellum link to neuroticism: a volumetric MRI association study in healthy volunteers. PLoS ONE. 2012;7:e37252.

59. Wei L, Duan X, Yang Y, Liao W, Gao Q, Ding JR, et al. The synchronization of spontaneous BOLD activity predicts extraversion and neuroticism. Brain Res. 2011;1419:68-75.

60. O'Gorman RL, Kumari V, Williams SC, Zelaya FO, Connor SE, Alsop DC, et al. Personality factors correlate with regional cerebral perfusion. Neuroimage. 2006;31:489-95.

61. Kelly RM, Strick PL. Cerebellar loops with motor cortex and prefrontal cortex of a nonhuman primate. J Neurosci. 2003;23: 8432-44.

62. Ito M. Control of mental activities by internal models in the cerebellum. Nat Rev Neurosci. 2008;9:304-13.

63. Lisman JE, Grace AA. The hippocampal-VTA loop: controlling the entry of information into long-term memory. Neuron. 2005;46: 703-13.

64. Bunzeck N, Düzel E. Absolute coding of stimulus novelty in the human substantia nigra/VTA. Neuron. 2006;51:369-79.

65. Schmajuk NA, Gray JA, Lam YW. Latent inhibition: a neural network approach. J Exp Psychol Anim Behav Process. 1996;22:321-49.

66. Middleton FA, Strick PL. Cerebellar projections to the prefrontal cortex of the primate. J Neurosci. 2001;21:700-12.

67. Hoshi E, Tremblay L, Féger J, Carras PL, Strick PL. The cerebellum communicates with the basal ganglia. Nat Neurosci. 2005;8: 1491-3.

68. Bostan AC, Dum RP, Strick PL. Cerebellar networks with the cerebral cortex and basal ganglia. Trends Cogn Sci. 2013;17: $241-54$
69. Rochefort C, Arabo A, André M, Poucet B, Save E, Rondi-Reig L. Cerebellum shapes hippocampal spatial code. Science. 2011;334: 385-9.

70. D'Angelo E, Casali S. Seeking a unified framework for cerebellar function and dysfunction: from circuit operations to cognition. Front Neural Circuits. 2012;6:116.

71. Mesulam MM. From sensation to cognition. Brain. 1998;121: 1013-52.

72. Rochefort C, Lefort JM, Rondi-Reig L. The cerebellum: a new key structure in the navigation system. Front Neural Circuits. 2013;13:7-35.

73. Iglói K, Doeller CF, Paradis AL, Benchenane K, Berthoz A, Burgess N, et al. interaction between hippocampus and cerebellum crus $\mathrm{i}$ in sequence-based but not place-based navigation. Cereb Cortex. 2015;25:4146-54.

74. Torriero S, Oliveri M, Koch G, Caltagirone C, Petrosini L. The what and how of observational learning. J Cogn Neurosci. 2007;19:1656-63.

75. Cutuli D, Rossi S, Burello L, Laricchiuta D, De Chiara V, Foti F, et al. Before or after does it matter? Different protocols of environmental enrichment differently influence motor, synaptic and structural deficits of cerebellar origin. Neurobiol Dis. 2011;42:9-20.

76. Foti F, Petrosini L, Cutuli D, Menghini D, Chiarotti F, Vicari S, et al. Explorative function in Williams syndrome analyzed through alarge-scale task with multiple rewards. Res Dev Disabil. 2011;32: 972-85.

77. Petrosini L, Molinari M, Dell'Anna ME. Cerebellar contribution to spatial event processing: Morris water maze and T-maze. Eur J Neurosci. 1996;8:1882-96.

78. Mandolesi L, Leggio MG, Spirito F, Petrosini L. Cerebellar contribution to spatial event processing: do spatial procedures contribute to formation of spatial declarative knowledge? Eur J Neurosci. 2003;18:2618-26.

79. Molinari M, Petrosini L, Misciagna S, Leggio MG. Visuospatial abilities in cerebellar disorders. J Neurol Neurosurg Psychiatry. 2004; 75:235-40.

80. Caston J, Chianale C, Delhaye-Bouchaud N, Mariani J. Role of the cerebellum in exploration behavior. Brain Res. 1998;808:232 7.

81. Fransen E, D’Hooge R, Van Camp G, Verhoye M, Sijbers J, Reyniers E, et al. L1 knockout mice show dilated ventricles, vermis hypoplasia and impaired exploration patterns. Hum Mol Genet. 1998;7:999-1009.

82. Rae C, Karmiloff-Smith A, Lee MA, Dixon RM, Grant J, Blamire $\mathrm{AM}$, et al. Brain biochemistry in Williams syndrome: evidence for a role of the cerebellum in cognition? Neurology. 1998;51:33-40.

83. Pierce K, Courchesne E. Evidence for a cerebellar role in reduced exploration and stereotyped behavior in autism. Biol Psychiatry. 2001;49:655-64.

84. Menghini D, Di Paola M, Federico F, Vicari S, Petrosini L, Caltagirone $\mathrm{C}$, et al. Relationship between brain abnormalities and cognitive profile in Williams syndrome. Behav Genet. 2011;41:394-402.

85. Cservenka A, Jones SA, Nagel BJ. Reduced cerebellar brain activity during reward processing in adolescent binge drinkers. Dev Cogn Neurosci; 2015

86. Delgado MR. Reward-related responses in the human striatum. Ann N Y Acad Sci. 2007;1104:70-88.

87. Palmiter RD. Dopamine signaling in the dorsal striatum is essential for motivated behaviors: lessons from dopamine-deficient mice. Ann N Y Acad Sci. 2008;1129:35-46.

88. Robbins TW, Everitt BJ. Neurobehavioural mechanisms of reward and motivation. Curr Opin Neurobiol. 1996;6:228-36.

89. Wise RA. Rewards wanted: molecular mechanisms of motivation. Discov Med. 2004;4:180-6. 
90. Moulton EA, Elman I, Pendse G, Schmahmann J, Becerra L, Borsook D. Aversion-related circuitry in the cerebellum: responses to noxiousheat and unpleasant images. J Neurosci. 2011;31:3795-804.

91. Barlow DH, Chorpita BF, Turovsky J. Fear, panic, anxiety, and disorders of emotion. Nebr Symp Motiv. 1996;43:251-328.

92. Benkelfat C, Bradwejn J, Meyer E, Ellenbogen M, Milot S, Gjedde A, et al. Functional neuroanatomy of CCK4-induced anxiety in normal healthy volunteers. Am J Psychiatry. 1995;152: 1180-4.

93. Chua P, Krams M, Toni I, Passingham R, Dolan R. A functional anatomy of anticipatory anxiety. Neuroimage. 1999;9:563-71.

94. Reiman EM. The application of positron emission tomography to the study of normal and pathologic emotions. J Clin Psychiatry. 1997;58:4-12.

95. Tillfors M, Furmark T, Marteinsdottir I, Fredrikson M. Cerebral blood flow during anticipation of public speaking in social phobia: a PET study. Biol Psychiatry. 2002;52:1113-9.

96. Rubio A, Van Oudenhove L, Pellissier S, Ly HG, Dupont P, de Micheaux HL, et al. Uncertainty in anticipation of uncomfortable rectal distension is modulated by the autonomic nervous system - a fMRI study in healthy volunteers. Neuroimage. 2015;107:10-22.

97. Yang X, Kendrick KM, Wu Q, Chen T, Lama S, Cheng B, et al. Structural and functional connectivity changes in the brain associated with shyness but not with social anxiety. PLoS One. 2013;8: e63151.

98. Bardo MT, Donohew RL, Harrington NG. Psychobiology of novelty seeking and drug seeking behavior. Behav Brain Res. 1996;77:23-43

99. Fresan A, Apiquian R, Nicolini H, Cervantes JJ. Temperament and character in violent schizophrenic patients. Schizophr Res. 2007;94:74-80

100. Loftus ST, Garno JL, Jaeger J, Malhotra AK. Temperament and character dimensions in bipolar I disorder: a comparison to healthy controls. J Psychiatr Res. 2008;42:1131-6.

101. Kumaran D, Maguire EA. Novelty signals: a window into hippocampal information processing. Trends Cogn Sci. 2009;13:47-54.

102. Fernandez M, Pissiota A, Frans O, von Knorring L, Fischer H, Fredrikson M. Brain function in a patient with torture related posttraumatic stress disorder before and after fluoxetine treatment: a positron emission tomography provocation study. Neurosci Lett. 2001;297:101-4.

103. Bonne O, Gilboa A, Louzoun Y, Brandes D, Yona I, Lester H, et al. Resting regional cerebral perfusion in recent posttraumatic stress disorder. Biol Psychiatry. 2003;54:1077-86.

104. Seidman LJ, Biederman J, Liang L, Valera EM, Monuteaux MC, Brown A, et al. Gray matter alterations in adults with attentiondeficit/hyperactivity disorder identified by voxel based morphometry. Biol Psychiatry. 2011;69:857-66.

105. Zarei M, Mataix-Cols D, Heyman I, Hough M, Doherty J, Burge $\mathrm{L}$, et al. Changes in gray matter volume and white matter microstructure in adolescents with obsessive-compulsive disorder. Biol Psychiatry. 2011;70:1083-90.

106. Cheng B, Huang X, Li S, Hu X, Luo Y, Wang X, et al. Gray matter alterations in post-traumatic stress disorder, obsessive-compulsive disorder, and social anxiety disorder. Front Behav Neurosci. 2015;9:219.

107. Durston S, van Belle J, de Zeeuw P. Differentiating frontostriatal and fronto-cerebellar circuits in attention-deficit/hyperactivity disorder. Biol Psychiatry. 2011;69:1178-84.

108. Moulton EA, Elman I, Becerra LR, Goldstein RZ, Borsook D. The cerebellum and addiction: insights gained from neuroimaging research. Addict Biol. 2014;19:317-31.

109. Bostan AC, Strick PL. The cerebellum and basal ganglia are interconnected. Neuropsychol Rev. 2010;20:261-70.
110. Goldstein RZ, Volkow ND. Drug addiction and its underlying neurobiological basis: neuroimaging evidence for the involvement of the frontal cortex. Am J Psychiatry. 2002;159:1642-52.

111. Goldstein RZ, Volkow ND. Dysfunction of the prefrontal cortex in addiction: neuroimaging findings and clinical implications. Nat Rev Neurosci. 2011;12:652-69.

112. Habas C, Kamdar N, Nguyen D, Prater K, Beckmann CF, Menon $\mathrm{V}$, et al. Distinct cerebellar contributions to intrinsic connectivity networks. J Neurosci. 2009;29:8586-94.

113. Volkow ND, Wang G-J, Fowler JS, Tomasi D, Telang F, Baler R Addiction: decreased reward sensitivity and increased expectation sensitivity conspire to overwhelm the brain's control circuit. BioEssays. 2010;32:748-55.

114. Dalwani M, Sakai JT, Mikulich-Gilbertson SK, Tanabe J, Raymond K, McWilliams SK, et al. Reduced cortical gray matter volume in male adolescents with substance and conduct problems. Drug Alcohol Depend. 2011;118:295-305.

115. Anderson CM, Maas LC, Frederick b, Bendor JT, Spencer TJ, Livni E, et al. Cerebellar vermis involvement in cocaine-related behaviors. Neuropsychopharmacology. 2006;31:1318-13126.

116. Allen G, Buxton RB, Wong EC, Courchesne E. Attentional activation of the cerebellum independent of motor involvement. Science. 1997;275:1940-3.

117. Bischoff-Grethe A, Ivry RB, Grafton ST. Cerebellar involvement in response reassignment rather than attention. J Neurosci. 2002;22:546-53.

118. Franken IH. Drug craving and addiction: integrating psychological and neuropsychopharmacological approaches. Prog Neuropsychopharmacol Biol Psychiatry. 2003;27:563-79.

119. Lisdahl KM, Thayer R, Squeglia LM, McQueeny TM, Tapert SF. Recent binge drinking predicts smaller cerebellar volumes in adolescents. Psychiatry Res. 2013;211:17-23.

120. Squeglia LM, Schweinsburg AD, Pulido C, Tapert SF. Adolescent binge drinking linked to abnormal spatial working memory brain activation: differential gender effects. Alcohol Clin Exp Res. 2011;35:1831-41.

121. Schweinsburg AD, McQueeny T, Nagel BJ, Eyler LT, Tapert SF. A preliminary study of functional magnetic resonance imaging response during verbal encoding among adolescent binge drinkers. Alcohol. 2010;44:111-7.

122. Xiao L, Bechara A, Gong Q, Huang X, Li X, Xue G, et al. Abnormal Affective decision making revealed in adolescent binge drinkers using a functional magnetic resonance imaging study. Psychol Addict Behav. 2013;27:443-54.

123. Buckner RL, Krienen FM, Castellanos A, Diaz JC, Yeo BT. The organization of the human cerebellum estimated by intrinsic functional connectivity. J Neurophysiol. 2011;106:2322-45.

124. Sifneos PE. Short-term psychotherapy and emotional crisis. Cambridge: Harvard University Press; 1972.

125. Bagby RM, Parker JD, Taylor GJ. The twenty-item Toronto Alexithymia Scale-I. Item selection and cross-validation of the factor structure. J Psychosom Res. 1994;38:23-32.

126. Bagby RM, Taylor GJ, Parker JD. The Twenty-item Toronto Alexithymia Scale-II. Convergent, discriminant, and concurrent validity. J Psychosom Res. 1994;38:33-40.

127. Taylor GJ. Recent developments in alexithymia theory and research. Can J Psychiatry. 2000;45:134-42.

128. Franz M, Schaefer R, Schneider C, Sitte W, Bachor J. Visual event-related potentials in subjects with alexithymia: modified processing of emotional aversive information? Am J Psychiatry. 2004;161:728-35.

129. Dorard G, Berthoz S, Haviland MG, Phan O, Corcos M, Bungener C. Multimethod alexithymia assessment in adolescents and young adults with a cannabis use disorder. Compr Psychiatry. 2008;49: 585-92. 
130. Honkalampi K, Hintikka J, Tanskanen A, Lehtonen J, Viinamäki $\mathrm{H}$. Depression is strongly associated with alexithymia in the general population. J Psychosom Res. 2000;48:99-104.

131. Larsen JK, Brand N, Bermond B, Hijman R. Cognitive and emotional characteristics of alexithymia: a review of neurobiological studies. J Psychosom Res. 2003;54:533-41.

132. Taylor GJ, Bagby RM. New trends in alexithymia research. Psychother Psychosom. 2004;73:68-77.

133. Kano M, Hamaguchi T, Itoh M, Yanai K, Fukudo S. Correlation between alexithymia and hypersensitivity to visceral stimulation inhuman. Pain. 2007;132:252-63.

134. Pouga L, Berthoz S, de Gelder B, Grèzes J. Individual differences in socioaffective skills influence the neural bases of fear processing: the case of alexithymia. Hum Brain Mapp. 2010;31:1469-81.

135. Reker M, Ohrmann P, Rauch AV, Kugel H, Bauer J, Dannlowski $\mathrm{U}$, et al. Individual differences in alexithymia and brain response to masked emotion faces. Cortex. 2010;46:658-67.

136. Moriguchi Y, Ohnishi T, Decety J, Hirakata M, Maeda M, Matsuda $\mathrm{H}$, et al. The human mirror neuron system in a population with deficient self-awareness: an fMRI study in alexithymia. Hum Brain Mapp. 2009;30:2063-76.

137. Grabe HJ, Wittfeld K, Hegenscheid K, Hosten N, Lotze M, Janowitz D, et al. Alexithymia and brain gray matter volumes in a general population sample. Hum Brain Mapp. 2014;35:5932-45.

138. Moriguchi Y, Komaki G. Neuroimaging studies of alexithymia: physical, affective, and social perspectives. Biopsychosoc Med. 2013;7:8.

139. Laricchiuta D, Petrosini L, Picerni E, Cutuli D, Iorio M, Chiapponi $\mathrm{C}$, et al. The embodied emotion in cerebellum: a neuroimaging study of alexithymia. Brain Struct Funct. 2015;220:2275-87.

140. Dimitrova A, Kolb FP, Elles HG, Maschke M, Forsting M, Diener $\mathrm{HC}$, et al. Cerebellar responses evoked by nociceptive leg withdrawal reflex as revealed by event-related FMRI. J Neurophysiol. 2003;90:1877-86.

141. Schraa-Tam CK, Rietdijk WJ, Verbeke WJ, Dietvorst RC, van den Berg WE, Bagozzi RP, et al. fMRI activities in the emotional cerebellum: a preference for negative stimuli and goal-directed behavior. Cerebellum. 2012;11:233-45.

142. Imaizumi S, Mori K, Kiritani S, Kawashima R, Sugiura M, Fukuda H, et al. Vocal identification of speaker and emotion activates different brain regions. Neuroreport. 1997;8:2809-12.

143. Wildgruber D, Riecker A, Hertrich I, Erb M, Grodd W, Ethofer T, et al. Identification of emotional intonation evaluated by fMRI. Neuroimage. 2005;24:1233-41.

144. Boyke J, Driemeyer J, Gaser C, Büchel C, May A. Traininginduced brain structure changes in the elderly. J Neurosci. 2008;28:7031-5.

145. Di Paola M, Caltagirone C, Petrosini L. Prolonged rock climbing activity induces structural changes in cerebellum and parietal lobe. Hum Brain Mapp. 2013;34:2707-14.

146. Pangelinan MM, Zhang G, VanMeter JW, Clark JE, Hatfield BD, Haufler AJ. Beyond age and gender: relationships between cortical andsubcortical brain volume and cognitive-motor abilities in school age children. Neuroimage. 2011;54:3093-100.

147. James CE, Oechslin MS, Van De Ville D, Hauert CA, Descloux C, Lazeyras F. Musical training intensity yields opposite effects on grey matter density in cognitive versus sensorimotor networks. Brain Struct Funct. 2014;219:353-66.

148. Fusar-Poli P, Placentino A, Carletti F, Landi P, Allen P, Surguladze $\mathrm{S}$, et al. Functional atlas of emotional faces processing: a voxel based meta-analysis of 105 functional magnetic resonance imaging studies. J Psychiatry Neurosci. 2009;34:418-32.

149. Konarski JZ, McIntyre RS, Grupp LA, Kennedy SH. Is the cerebellum relevant in the circuitry of neuropsychiatric disorders? J Psychiatry Neurosci. 2005;30:178-86.
150. Murphy FC, Nimmo-Smith I, Lawrence AD. Functional neuroanatomy of emotions: a meta-analysis. Cogn Affect Behav Neurosci. 2003;3:207-33

151. Andela CD, van der Werff SJ, Pannekoek JN, van den Berg SM, Meijer OC, van Buchem MA, et al. Smaller grey matter volumes in the anterior cingulate cortex and greater cerebellar volumes in patients with long-term remission of Cushing's disease: a casecontrol study. Eur J Endocrinol. 2013;169:811-9.

152. de Wit SJ, Alonso P, Schweren L, Mataix-Cols D, Lochner C, Menchón JM, et al. Multicenter voxel-based morphometry mega-analysis of structural brain scans in obsessive-compulsive disorder. Am J Psychiatry. 2014;171:340-9.

153. Koziol LF, Budding DE, Chidekel D. From movement to thought: executive function, embodied cognition, and the cerebellum. Cerebellum. 2012;11:505-25.

154. Wang D, Buckner RL, Liu H. Functional specialization in the human brain estimated by intrinsic hemispheric interaction. $\mathrm{J}$ Neurosci. 2014;34:12341-52.

155. Schmahmann JD, Pandya DN. The cerebrocerebellar system. Int Rev Neurobiol. 1997;41:31-60.

156. Anders S, Lotze M, Erb M, Grodd W. Birbaumer N Brain activity underlying emotional valence and arousal: a response-related fMRI study. Hum Brain Mapp. 2004;23:200-9.

157. Barsalou LW. Grounded cognition. Annu Rev Psychol. 2008;59: 617-45.

158. Niedenthal PM, Barsalou LW, Krauth-Gruber S, Winkielman P, Ric F. Embodiment in attitudes, social perception, and emotion. Pers Soc Psychol Rev. 2005;9:184-211.

159. Varela FJ, Thompson E, Rosch E. The embodied mind: cognitive science and human experience. Cambridge: MIT Press; 1991.

160. Lakoff G, Johnson M. Philosophy in the flesh: the embodied mind and its challenge to western thought. New York: Basic Books; 1999.

161. Clark A. Being there. Putting brain, body and world together again. Cambridge: MIT Press; 1997.

162. Hurley SL. Consciousness in action. Cambridge: Harvard University Press; 1998.

163. Gallagher S. How the body shapes the mind. New York: Clarendon Press; 2005.

164. Damasio AR. The somatic marker hypothesis and the possible functions of the prefrontal cortex. Philos Trans R Soc Lond B Biol Sci. 1996;351:1413-20.

165. Fuchs T, Koch SC. Embodied affectivity: on moving and being moved. Front Psychol. 2014;5:508.

166. Duddu V, Isaac MK, Chaturvedi SK. Alexithymia in somatoform and depressive disorders. J Psychosom Res. 2003;54:435-8.

167. Cisek P, Kalaska JF. Neural mechanisms for interacting with a world full of action choices. Annu Rev Neurosci. 2010;33:269-98.

168. Cisek P, Pastor-Bernier A. On the challenges and mechanisms of embodied decisions. Philos Trans R Soc Lond B Biol Sci. 2014;369:1655.

169. Friston K, Schwartenbeck P, FitzGerald T, Moutoussis M, Behrens T, Dolan RJ. The anatomy of choice: dopamine and decisionmaking. Philos Trans R Soc Lond B Biol Sci. 2014;369:1655.

170. Critchley HD, Mathias CJ, Josephs O, O’Doherty J, Zanini S, Dewar $\mathrm{BK}$, et al. Human cingulate cortex and autonomic control: converging neuroimaging and clinical evidence. Brain. 2003;126:2139-52.

171. Lane RD, Ahern GL, Schwartz GE, Kaszniak AW. Is alexithymia the emotional equivalent of blindsight? Biol Psychiatry. 1997;42:834 44.

172. Pezzulo G, Castelfranchi C. The symbol detachment problem. Cogn Process. 2007;8:115-31.

173. Pezzulo G, Castelfranchi C. Intentional action: from anticipation to goal-directed behavior. Psychol Res. 2009;73:437-40. 